\section{Farklı Yürüyüş Hızlarında Adım Uzunluğundan Boy Tahmini}

\author{
Işık Ecem KILIÇ ${ }^{1 *} \odot$ \\ ${ }^{1}$ Arş. Gör., Başkent Üniversitesi, Temel Tıp Bilimleri Bölümü, Anatomi Anabilim Dalı, Ankara/TÜRKiYE
}

$\ddot{\alpha}_{z}$

Güvenilir bir kimliklendirmenin gerçekleştirilebilmesi için, boy cinsiyet etnik köken ve ölüm anındaki yaş önemlidir. Bu araştırma olay yerini terk eden zanlının kimliklendirilebilmesi için elde herhangi bir kalıntı olmadığı durumlarda zanlı sayısını azaltabilmek adına suç mahallinde bulunan ayak izleri arası adım uzunluğundan suçlunun boyunu tahmin edebilmek amacıyla gerçekleştirilmiştir. Çalışma Başkent Üniversitesi öğrencisi olan ya da Başkent Üniversitesi personel kadrosunda görev yapan 104 erkek 102 kadın toplam 206 birey üzerinde yürütülmüştür. Katılımcıların yaşları 18 ile 49 arasında değişmektedir. Tüm katılımcılardan boy ve ağırlık ölçümlerinin yanı sıra ayak uzunluğu ölçümleri ve iki farklı hız için tek adım ve çift adım uzunlukları ölçülmüştür. Yürüme hızları erkek katılımcılar için $3,3 \mathrm{~km} / \mathrm{s}$ ve $5,3 \mathrm{~km} / \mathrm{s}$, kadınlar içinse $2,7 \mathrm{~km} / \mathrm{s}$ ve 4,7 $\mathrm{km} / \mathrm{s}$ olarak belirlenmiştir. Kadınlarda boy ile adım uzunlukları arasında değişen zayıf ancak istatistiksel olarak anlamlı ilişki tespit edilmiştir $(r=$ 0,300 - 0,384). Benzer şekilde, erkeklerde de boy ile adım uzunlukları arasında değişen zayıf ancak istatistiksel olarak anlamlı ilişki bulunmuştur $(r=0,255-0,333)$. Ancak adım uzunluğundan yola çıkarak boy tahminine gidilen bu çalışmada elde edilen regresyon eşitliklerini açılayıcılık kat sayılarının çok düşük olduğu gözlenmiştir. Sonuç olarak tek adım ve çift adım uzunluklarının boy tahmini için uygun bağımsız değişkenler olmadığı sonucuna ulaşılmışır.

Anahtar Sözcükler: Adım uzunluğu, boy tahmini, yürüyüş hızı

\section{Giriş}

Adli soruşturmaların en önemli kısmı kimliklendirme aşamasıdır. Mağdur, maktul ya da failin olayla ilişkisinin araştırılması ve gerçeğin ortaya çıarılabilmesi bakımından kimliklendirmede başarı esastır. Öte yandan kamu vicdanın aydınlatılması, maktullerin ya da felaket kurbanlarının yakınlarının şüphelerinin giderilmesi bakımından adli analizler ve kimliklendirme çalışmaları hayati derecede önemlidir.

Boy, yaş, cinsiyet ve etnik köken güvenilir bir kimliklendirme için gerekli olan dört ana öğedir (Pelin vd., 2010). Söz konusu ana değişkenlerin yan sıra kimliklendirmede bireyin engellilik hali, kullanılan

\section{Height estimation from the step length at different walking speeds}

Abstract

Footprints available in the crime scene by the offender could be evaluated for identification if there is not any other evidence. The aim of the present study is to estimate stature from step length depending on the distance between footprints. The study is conducted on 104 male and 102 female a total of 206 individuals. All the participants were either the students of Baskent University or the staff working for Basskent University. Stature on body weight of all participants were measured and reported. In addition step length and stride length were taken for two different walking speeds. Walking speed were $3,3 \mathrm{~km} / \mathrm{h}$ and $5,3 \mathrm{~km} / \mathrm{h}$ for males, $2,7 \mathrm{~km} / \mathrm{h}$ and $4,7 \mathrm{~km} / \mathrm{h}$ for females. For female subjects statistically significant positive correlation was found between stature and step length and stride length, both for $2,7 \mathrm{~km} / \mathrm{h}$ and $4.7 \mathrm{~km} / \mathrm{h}(r=0,300-0,384$ respectively). In males significant positive correlations between stature and step and stride lengths both for $3,3 \mathrm{~km} / \mathrm{h}$ and $5,3 \mathrm{~km} / \mathrm{h}$ were also observed ( $r=0,255-0,333)$. However, it was observed that the regression coefficients obtained from the step and stride length were very low. It could be concluded that step and stride lengths are not suitable independent variables for stature estimation.

Key Words: Step length, stature estimation, walking speed

protez veya çeşitli medikal aparatlar, yumuşak doku kaybının tam olmadiğ1 durumlarda yara izleri veya dövmelerin uyuşup uyuşmadığını ortaya çıkararak, en doğru sonuca ulaşmak amaçlanmaktadır. Olay yerini terk etmiş olan suçlunun saptanması doğrultusunda gerçekleştirilen adli incelemeler, suç mahallinden, olay yeri inceleme uzmanlarının topladığ1 deri kalıntısı, saç teli, parmak izi, 1sırık, dudak izi, kan ve vücut sıvısı gibi verilerin zanlılardan alınan örneklerle karşılaştırılması esasina dayanir.

Bu çalışmada amacımız elde herhangi bir delilin bulunmamas1 durumunda olay yerinde bulunan ayak izleri arasındaki mesafelerden yola çıkarak suçlu bireyin 
boyuna ilişkin güvenilir bir yaklaşımda bulunmaktır.

Boy tahmininde matematik ve anatomik yöntemler olmak üzere iki teknik kullanılmaktadır (Lundy, 1985). Anatomik yöntemde boya doğrudan katkıs1 bulunan kemikler normal anatomik konumlarına göre bir araya bir araya getirilip yumuşak dokular için bir düzeltme faktörü göz önünde bulundurularak boy uzunluğuna yönelik fikir edinilmektedir. İlk kez Dwight tarafindan uygulanan yöntemde söz konusu kemikler kil kullanılarak bir arada tutulmuşlardır (Dwight, 1894). Daha sonra Fully iskeleti bir bütün halinde değil de boya katkısı olan kemikleri ayrı ayrı ölçmüş ve bir düzeltme faktörü ile birlikte değerlendirmiştir (Fully, 1956). Bu teknik boy uzunluğuna ilişkin oldukça güvenilir sonuçlar vermektedir. Ancak neredeyse iskelet kemiklerinin tamamının elde bulundurulması gerektiğinden özellikle adli vakalarda kullanım yüksek oranda kısıtlanmaktadır.

Matematik yöntemde ise herhangi bir kemikten alınan ölçümün kişinin boyuna olan oranı dikkate alınmaktadır. Var olan bağımsız bir değişkenden alınan verilerle tahminde bulunulur. Sözü edilen oranların vücut gelişimi tamamlanmış olan erişkin bireylerde değişmediği bilinmektedir Boy tahmini araştırmalarında gerçeğe en yakın sonuçlara uzun kemik ölçümlerinden, boy uzunluğuna doğrudan katkısı dikkate alındığında ise, alt ekstremite uzun kemiklerinden elde edilen verilere dayanılarak oluşturulan regresyon formülleriyle ulaşıldığı bilinmektedir (Pelin, 2014). Ancak gerek adli antropoloji gerek biyoarkeoloji çerçevesinde yapılan çalışmalarda uzun kemiklerin bütün ve sağlam olarak elde edilmesi her zaman mümkün olmayabilir. Boy tahmini günümüzde adli soruşturmalarda büyük önem tassımaktadır. Adli soruşturma gerektiren durumlarda olay yeri incelemesi yapilır. Boy tahminine ilişkin günümüze kadar çeşitli çalışmalar gerçekleştirilmiştir. Ancak bireye ilişkin herhangi bir beden bölümünün elde bulunmadığ 1 durumlarda bu tahminin yapilmas1 mümkün olamaz. Olay yerinde gözlenen ayak izleri araştırmacılara özellikle olay yerini terk etmiş olan bireyin, muhtemelen suçlunun boyuna ilişkin bilgi verebilir. Gerek ayak izinin boyutları gerekse adım uzunluğu bu doğrultuda yol gösterici olabilir.

Adım uzunluğu tek adım ve çift adım uzunluğu diye ayrı ayrı hesaplanabilir. Tek adım uzunluğu yürüme esnasında adım atılan ayağın topuk vuruşu ile diğer ayağın topuk vuruşu arasındaki mesafeyi ifade eder. Çift adım uzunluğu ise aynı ayağın iki topuk vuruşu arasındaki mesafeyi ifade eder (İnal, 2017). Ancak adım uzunluğunun bireyin yürüyüş hızına bağlı olarak değişebileceği düşünülmektedir.

Çalışmamızda olay yerinde bulunan adımlar arası mesafe göz önüne alınarak ç1kartılan adım uzunluklarından olaya karışan kişilerin boyları hesaplanabilir mi diye değerlendirmek amaçlanmıştır.
Bulunan tahmini boy uzunlukları göz önüne alınarak suça karışan ya da karışmayan kişilerin sayısının azaltılması veya suçlunun daha iyi tespit edilebilmesi, zanlı sayısının azaltılması amaçlanmaktadır.

\section{Gereç ve Yöntem}

Çalışma Başkent Üniversitesi öğrencisi olan ya da Başkent Üniversitesi personel kadrosunda görev yapan 104 erkek 102 kadın toplam 206 birey üzerinde yürütülmüştür. Katılımcıların yaşları 18 ile 49 arasında değişmektedir. Herhangi bir kalp ve akciğer hastalı̆̆ olan ve bu doğrultuda ilaç kullanan kişiler ile herhangi bir alt ekstremite sakatlığı olan bireyler çalışmaya dahil edilmemiş olup, ölçümler Mayıs 2018-Haziran 2019 tarihleri arasında alınmıştır .

Tüm katılımcılardan boy ve ağırlık ölçümlerinin yanı sıra ayak uzunluğu ölçümleri ve iki farklı hız için tek adım ve çift adım uzunluk ölçümleri alınmıştır.

Adım uzunlukları yürüme bandı üzerinde kadın ve erkek bireyler için belirlenmiş olan iki farklı hızda Optojump adı verilen alet yürüme bandının kenar kısımlarına yerleştirilerek ölçülmüştür (Resim 1). Optojump, Rago ve arkadaşları (2018) tarafindan yürütülen bir çalışmada, adım uzunluğu ölçümleri alınırken kullanılmış ve güvenilirliği kanıtlanmıştır. Söz konusu ölçümler için Qualisys Running Analysis ve Matlab Walk Data'nın da altın standart olarak kullanılmasına karşın Rago ve arkadaşlarının (2018) çalışmasının güvenilirliğine dayanarak Optojump kullanmaya karar verildi (İnal, 2017).

Optojump; yürüyüş bir ayağın topuk vuruşu ile diğer ayağın topuk vuruşu arasında gerçekleştiğinden dolay1 yürüyüşe başlanılan ayağın uzunluğu kalırken, diğer ayağın uzunluğunu yürüme döngüsünden çıkartıp sadece adımlar arasındaki mesafeyi ölçüyordu. Bu sebepten dolayı alet kendisi yürüyüş hızını ölçmeden önce ayak uzunluğunu ölçmemizi öngörüyordu. Optojump yürüme bandı üzerine çıan kişinin ayak uzunluğu ölçümünü kendi alıyordu. Katılımcilardan yürüme bandının üzerine çıkıp, önce tek ayak üzerinde durmaları istenerek ayak uzunlukları ölçümleri alındı. Bütün ölçümlere önce ayak uzunluğu alınarak başlandı. Ayak uzunluğu ölçümleri katılımcıların yürüme bandı üzerine çıkıp tek ayak üzerinde durmaları istenilerek alındı. Ölçümler ayakkabı ile alındı. Ölçüm sırasında giyilen ayakkabılar aletin uzunluk ölçümü almasına izin verecek şekilde düz tabanlı ayakkabılardı.

Adım uzunlukları gerek kadın gerekse erkek bireyler için daha önceden belirlenmiş olan iki farklı hızda birer dakika boyunca yürünürken alınmıştır. Çalışmamızda yürüyüş hızlarını Whittle' in 2007 yılında yapmış olduğu ve ortalama yürüme hızı hesapladığı çalışmayı baz alarak belirledik (Whittle, 2007). Biz çalışmamızı yaşları 1849 arasinda değissen bireyler üzerinde yürüttüğümüz 


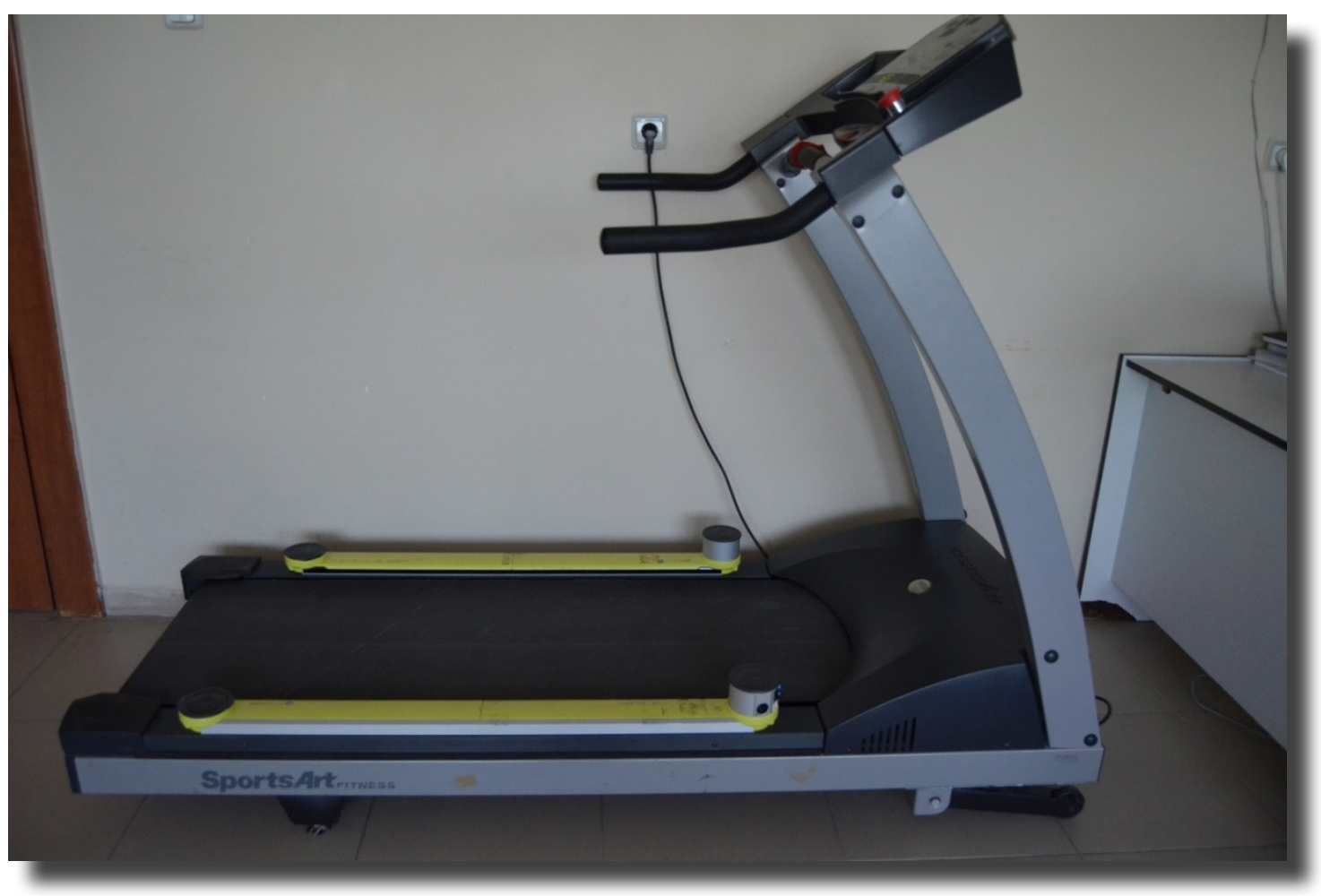

Resim 1. Optojump yürüme bandının üzerine terleştirildikten sonra

için Whittle'ın 18-49 yaş arası erişkin bireylerden almış olduğu ölçümlerle ortaya koyduğu yürüme hızlarını kullanarak adım uzunluğunu değerlendirdik (Whittle, 2007).

Kişilerin boyları Martin tip antropometre ile ölçüldü. Kişilerin boyları ve adım uzunlukları ölçümleri santimetre cinsinden alındı. Kiloları, cinsiyetleri ve doğum tarihleri kaydedildi. Daha sonra toplanan bütün verilerin girişi yapıldı. Bütün ölçümler aynı araştırmacı tarafindan günün aynı saatinde alındı

Ölçümlerimiz yürüme band1 üzerinde yapıldı. Yürüme bandının gösterdiği $\mathrm{km} / \mathrm{s}$ hızının doğruluğu test edildi. Yürüme bandının hızı 2,0 km/s hızına ayarlandı. Bandın üzerine bir adet bașlangıç bir adet bitiș noktasına denk gelecek şekilde tıbbi beyaz flaster yapıştırıldı. Flaster ile aynı ölçüde bir cisim bant $2,0 \mathrm{~km} / \mathrm{s}$ hızında çalışırken bir cisim bırakıldı. Ve yürüme bandı yarım turu tamamladığında cisim üzerinden çekildi. Her turda bu işlem tekrarlandı. Bu sırada Optojump'a hız girişi yapılmadı. Optojump'ın, yürüme bandının üzerindeki cismin hızını kendisinin ölçmesi ve yürüme bandının verdiği hızın doğruluğunun ölçülmesi amaçlandı. Bu ölçümler her hız için üç kez tekrarlandı. Birinci ölçümde Optojump $2,02 \mathrm{~km} / \mathrm{s}$ hız gösterdi. İkinci ve üçüncü ölçümlerde 2,0 km/s hız gösterdi. Ölçümlerin hepsi için bu işlem tekrarlandı. Kadın katılımcılar için 2,7 $\mathrm{km} / \mathrm{s}$ ve $4,7 \mathrm{~km} / \mathrm{s}$ hızlarında ölçüm yapılması sebebiyle bu hızlarda tekrar denendi. Erkek katılımcılar için 3,3 $\mathrm{km} / \mathrm{s}$ ve $5,3 \mathrm{~km} / \mathrm{s}$ hızlarında tekrarlandı. Optojump hizı kendisi tespit ediyordu ve yürüme bandıyla aynı sonucu verdi.
Her bir cinsiyet grubundaki bireylerin \%10'undan ikincilölçümleralınarakgüvenirliğindeğerlendirilmesinde Sınıf-içi korelasyon katsayısı hesaplanmıştır (Tablo 1). Cinsiyet gruplarında boy uzunluğu ile adım uzunlukları arasındaki ilişkinin gücünün ve yönünün incelenmesi amaciyla Spearman korelasyon katsayısı kullanılmıştır. Boyun adım uzunluğu kullanılarak tahmin edilebilmesi için basit doğrusal regresyon analizi uygulanmıştır. Tüm analizler için yanılg1 düzeyi $\alpha=0.05$ olarak belirlenmiştir. Analizlerin tamam1 SPSS v17.0 (Statistical Package for Social Science for Windows version 17.0, Chicago, IL, USA - Eylül 2012 lisans numarası: 1093910, Başkent Üniversitesi) kullanılarak gerçekleştirilmiştir.

Tablo 1. Ölçümlere ilişkin sınıf-içi korelasyon katsayıları

\begin{tabular}{ccc}
\hline & $\begin{array}{c}\text { Sinıf-İçi Korelasyon } \\
\text { Katsayısı }\end{array}$ & $\mathrm{p}$ \\
\hline KADINLAR & 0,886 & 0,005 \\
Tek adım 2,7* & 0,942 & 0,001 \\
Çiftadım 2,7 & 0,891 & 0,001 \\
Tek adım 4,7* & 0,884 & 0,005 \\
Çiftadım 4,7 & & \\
ERKEKLER & & \\
Tek adım 3,3* & 0,942 & 0,001 \\
Çiftadım 3,3 & 0,746 & 0,035 \\
Tek adım 5,3* & 0,767 & 0,027 \\
Çiftadım 5,3 & 0,752 & 0,033 \\
\hline
\end{tabular}

* km/saat olarak yürüme hızı 


\section{Bulgular}

Gerek kadın gerekse erkek bireylerde farklı yürüyüş hızlarında tek ve çift adım uzunluklarına ilişkin değerler Tablo 2'de yer almaktadır.

Tablo 2. Ölçümlere ilişkin ortalama, standart sapma, en az ve en çok değerlersınıf-içi korelasyon katsayıları

\begin{tabular}{|c|c|c|c|}
\hline \multirow{2}{*}{ Cinsiyet } & \multicolumn{3}{|c|}{ Ortalama \pm SS } \\
\hline & & Ortanca & En az - En çok \\
\hline \multirow{4}{*}{ KADIN } & Tek adım 2,7 & $\begin{array}{c}51,44 \pm 4,27 \\
51,11\end{array}$ & $39,30-61,74$ \\
\hline & Çift adım 2,7 & $\begin{array}{c}102,57 \pm 8,56 \\
102,25\end{array}$ & $78,68-123,64$ \\
\hline & Tek adım 4,7 & $\begin{array}{c}68,30 \pm 4,77 \\
68,38\end{array}$ & $40,05-76,38$ \\
\hline & Çift adım 4,7 & $\begin{array}{c}136,43 \pm 9,72 \\
136,70\end{array}$ & $80,14-152,72$ \\
\hline \multirow{5}{*}{ ERKEK } & Tek adım 3,3 & $\begin{array}{c}59,03 \pm 4,81 \\
58,47\end{array}$ & $49,62-72,87$ \\
\hline & Çift adım 3,3 & $\begin{array}{c}117,88 \pm 9,50 \\
116,93\end{array}$ & $99,24-145,75$ \\
\hline & & & \\
\hline & Tek adım 5,3 & $\begin{array}{c}77,0 \pm 10,71 \\
75,73\end{array}$ & $61,30-87,25$ \\
\hline & Çift adım 5,3 & $\begin{array}{c}151,98 \pm 9,89 \\
151,18\end{array}$ & $122,53-175,15$ \\
\hline
\end{tabular}

Hem erkeklerde hem de kadınlarda boy uzunlukları ile adım uzunlukları arasındaki korelasyonların gücü zayıftır. $\mathrm{Bu}$ nedenle cinsiyet gruplarında, boy uzunluğunun tahmini için adım uzunluğu kullanılarak yeterli modeller elde edilip edilemeyeceği incelenmiştir. Ancak yeterli bir modelin elde edilebilmesi için bağıml ve bağımsız değişken arasındaki ilişkinin en az orta düzeyde olması beklenmektedir.

Tek ve çift adım uzunluğu tüm hızlarda bağımsız değişken olarak düşünüldüğünde, boy uzunluğunun tahmini için elde edilen basit doğrusal regresyon modelleri tümel olarak anlamlıdır. Modellere ilişkin açıklayıcılık katsayıları $\left(\mathrm{R}^{2}\right)$ ise oldukça düşük bulunmuştur (Tablo 3).

\section{Tartışma}

Boy tahmininin adli olgularda güvenilir bir kimliklendirmenin gerçekleştirilmesi doğrultusunda taşıdığ1 önemin yanı sıra, biyolojik antropoloji alanında iskelet toplumlar değerlendirilirken, toplumun morfolojik ve demografik durumunun, çevre şartları ve gida potansiyellerinden etkilenme durumunun açığa çıkartılması açısından da rol gösterici niteliktedir
(Holliday, 2002; Benjamin vd., 2010). Vücut birimlerinden yola çıkılarak boy tahminine ilişkin çok sayıda çalışma gerçekleştirilmiştir. Biz çalışmamızda özellikle saldırganın kimliklendirilmesi amaciyla olay yerinden elde edilen adım izlerinden boy tahmininin hesaplanması amaçlanmıştır.

Alt ekstremite birimlerinden alınan ölçümlere dayanılarak yapılan boy tahminlerinin oldukça güvenilir sonuçlar verdiği bilinmektedir (Özaslan vd., 2003; Atamtürk ve Duyar, 2008; Wilson vd., 2010; Mahakkanukrauh vd., 2011; Asadujjaman ve Molla, 2019). Adım uzunluğunun özellikle alt ekstremite uzunlukları ile bağlantısını göz önünde bulundurarak boy tahmininde adım uzunluğundan yola çıkılarak oluşturulan eşitliklerin güvenilirliğini değerlendirmeyi ve alt ekstremite bilimlerinden alınan boy tahminine ilişkin diğer eşitliklerle karşılaştırmayı amaçladık.

Özaslan ve arkadaşları alt ekstremite ölçümlerinden oluşturdukları regresyon modeli ile uyluk uzunluğu, bacak uzunluğu, malleolyüksekliği, ayak uzunluğu ve ayak genişliği ile değişik denklemler elde etmişlerdir. Boy ile en iyi korelasyonu içeren değişken malleol yüksekliğidir ve açıklayıcılık katsayısı kadınlar için $\mathrm{R}^{2}=0,76$, erkekler için $R^{2}=0,75$ olarak ortaya konulmuştur (Özaslan vd., 2003).

Mahakkanukrauh ve arkadaşları (2011) ise boy tahmininde üst ve alt ekstremitede bulunan altı kemikten alınan ölçümler ile yapılan tahminlerin güvenilirliklerini değerlendirmişlerdir (Mahakkanukrauh vd., 2011). Femurun boy tahmini bağlamında daha önce yapılmış olan çalışmalarda güvenilirliği en yüksek eşitlikleri verdiği bilinmektedir (Wilson vd., 2010). Bu sonucu Mahakkanukrauh femurun çevre koşullarından ve beslenmeden görece daha az etkilenmesinden dolayı olabileceğine ve femurun boy üzerindeki katkısının diğer kemiklere nazaran daha yüksek olmasından kaynaklanabileceğine bağlamıştır. Aynı zamanda üst ekstremitede bulunan kemikler ile yapılan çalışmaların güvenilirlik düzeyinin daha düşük olduğu bilinmektedir. Mahakkanukrauh kendi çalışmasında bulunan standart hatanın üst ekstremitede alt ekstremiteden 0,5 santimetre daha fazla olduğunu belirtmektedir. Eşitlikler güvenilirlik anlamında değerlendirildiklerinde erkeklerdeki en yüksek korelasyon katsayısını femur $\left(\mathrm{R}^{2}=0,769\right)$ verirken, bunu fibula $\left(\mathrm{R}^{2}=0,767\right)$ ve tibia $\left(\mathrm{R}^{2}=0,759\right)$ takip etmektedir. Kadınlarda da sonuçlar benzer sıralama ile elde edilmiştir. Korelasyon katsayısı en yüksek olan femur $\left(\mathrm{R}^{2}=0,762\right)$ iken, sonrasında tibia $\left(R^{2}=0,678\right)$ ve fibula $\left(R^{2}=0,668\right)$ ile takip etmektedir.

Atamtürk ve Duyar (2008) ayak izi ve ayak ölçümleri alınarak boy ve kilo hesaplanması için, yaş ve cinsiyete yönelik çalışmışlardır. Boy tahmini yapabilmek amacıyla oluşturdukları regresyon denklemleri içerisinde, ayak uzunluğu ve genişliği, topuk genişliği, ayak izi uzunluğu 
Tablo 3. Kadın ve erkek adım uzunluklarının boy uzunluğu tahmini için regresyon modelleri istatistikleri

\begin{tabular}{|c|c|c|}
\hline \multicolumn{3}{|l|}{ KADIN } \\
\hline Tek adım uzunluğu 2,7=143.922+0.403×Tek Adım 2,7 & $\mathrm{R}^{2}=0,111 \mid \mathrm{r}=0,334$ & $\mathrm{~F}=12,525 \mid \mathrm{p}=0,001$ \\
\hline Çift adım uzunluğu 2,7=146,082+0,181×Çift Adım 2,7 & $\mathrm{R}^{2}=0,09 \mid \mathrm{r}=0,300$ & $\mathrm{~F}=9,918 \mid \mathrm{p}=0,002$ \\
\hline Tek adım uzunluğu 4,7=133,001+0,461×Tek Adım 4,7 & $\mathrm{R}^{2}=0,118 \mid \mathrm{r}=0,344$ & $\mathrm{~F}=13,271 \mid \mathrm{p}<0,001$ \\
\hline Çift adım uzunluğu 4,7=130.405+0.25×Çift Adım 4,7 & $\mathrm{R}^{2}=0,148 \mid \mathrm{r}=0,384$ & $\mathrm{~F}=17,131 \mid \mathrm{p}<0,001$ \\
\hline \multicolumn{3}{|l|}{ ERKEK } \\
\hline Tek adım uzunluğu 3,3 =154.957+0.410×Tek Adım 3,3 & $\mathrm{R}^{2}=0,107 \mid \mathrm{r}=0,327$ & $\mathrm{~F}=11,975 \mid \mathrm{p}<0,001$ \\
\hline Çift adım uzunluğu 3,3=154.283+0.211×Çift Adım 3,3 & $\mathrm{R}^{2}=0,111 \mid \mathrm{r}=0,333$ & $\mathrm{~F}=12,430 \mid \mathrm{p}=0,001$ \\
\hline Tek adım uzunluğu 5,3=153,675+0,337×Tek Adım 5,3 & $\mathrm{R}^{2}=0,068 \mid \mathrm{r}=0,260$ & $\mathrm{~F}=7,353 \mid \mathrm{p}=0,008$ \\
\hline Çift adım uzunluğu 5,3=154,709+0,162×Çift Adım 5,3 & $\mathrm{R}^{2}=0,065 \mid \mathrm{r}=0,255$ & $\mathrm{~F}=7,024 \mid \mathrm{p}=0,009$ \\
\hline
\end{tabular}

ve genişliği, ayak izi topuk genişliği değişkenlerini içeren denklemin en iyi sonucu verdiğini ifade etmişlerdir. Çalışmanın bu değişkenleri içeren regresyon denkleminde açıklayıcılık katsayısını $\mathrm{R}^{2}=0,807$ olarak gözlemlemişlerdir (Atamtürk ve Duyar, 2008); ancak doğrudan ayak izinin boyutlarını değerlendirmişlerdir. Söz konusu ölçümler ayağa ilişkin boyutları yansıtmalarından dolayı açıklayıcılık katsayıları görece daha yüksek olarak saptanmıştır. Biz çalışmamızda ayak izleri arasındaki mesafeden yola çıkarak boy tahmininde bulunduk.

Asadujjaman ve arkadaşları çalışmalarında 150 erkek, 150 kadın toplam 300 kişiden aldıkları ölçümler ile boy tahminine gitmişlerdir. Asadujjaman ve arkadaşları çalışmalarında katılımcıların ayak uzunlukları ve genişlikleri de dahil olmak üzere toplamda yedi ölçüm üzerinden model oluşturmuşlardır ve ölçümler dokudan direk alınmıştır (Asadujjaman vd, 2019, 1-8). Bizim çalışmamız ise ayaktan alınan ölçümler ile değil, adım uzunluğundan alınan ölçümler ile yapılmıştır. Çalışmamızda ayaktan alınan ölçümler ile boya ilişkin ortaya konulan modellemelerin güvenirliğinin yüksek olduğu baz alınarak hipotezimizi planlamıştık. Ancak ayak bir vücut bileşenidir ve boya doğrudan etkisi vardır. Adım uzunluğu ise boya doğrudan katkısı olan bir bileşen değildir ve bu sebepten dolayı bizim çalışmamızın tahmini standart hatası daha yüksek, R2 değerleri ise daha düşük çıkmıştır.

\section{Sonuç}

Alt ekstremite ölçümlerinden yola çı1kılarak ortaya konulan eşitliklerin görece yüksek tahminler verdiğini göz önünde bulundurarak başlattığımız bu çalışmanın bulguları hipotezimizi desteklemedi. Adım uzunluğu el, ayak boyutları gibi vücut yapısını açıklayıcı nitelikte olmadığ1 gibi alt ekstremite uzun kemikleri gibi boya direkt katkı da sağlamamaktadır. Dolaysıyla da bir bağımsız değişken olarak gücü azalmaktadır. Bunların yanı sıra yürüme şeklini ve hızını etkileyen çok sayıda faktör bulunmaktadır; alt ekstremitede gerek kemik, gerek eklem, gerekse kasları etkileyen en ufak bir patoloji hem yürüme şeklini hem de hızını etkileyecektir. Yaş, kültür, cinsiyet, meslek hatta bireyin uzun süre yapmış olduğu veya yapmakta olduğu spor da yürüme üzerinde etkilidir (Bejek vd., 2006).

Her ne kadar adim uzunluklarına dayanılarak boy tahminine ilişkin olarak çalışmamızda geliştirilmiş olan eşitlikler istatistiksel olarak anlamlı olsalar da yeterince güvenilir değillerdir ve adli alanda kullanımları uygun değildir.

\section{Kaynakça}

Asadujjaman, M., Al Noman, S. N., ve Molla, M. B. A. (2019). Stature estimation from foot anthropometric measurements in Bangladeshi population, Irish Journal of Medical Science, 1-8. DOI: $10.1007 /$ s11845-019-02048-x

Atamturk, D., ve Duyar, I. (2008). Age Related factors in the relationship between foot measurements and living stature and body weight, Journal of Forensic Sciences, 53(6), 1296- 1300. DOI: $10.1111 / \mathrm{j} .1556-4029.2008 .00856 . \mathrm{x}$

Auerbach, B. M., ve Ruff, C. B. (2010). Stature estimation formulae for indigenous North American populations, American Journal of Physical Anthropology, 141(2), 190-207. DOI: 10.1002/ ajpa. 21131

Bejek, Z, Paróczai, R, Illyés, A., ve Kiss R. M. (2006). The influence of walking speed on gait parameters in healthy people and in patients with osteoarthritis, Knee Surgery, Sports Traumatology, Arthroscopy, 14(7), 612-622. DOI: 10.1007/s00167-005-0005-6

Dwight, T. (1894). Methods of estimating the height from parts of the skeleton, Medical Record (1866-1922), 46(10), 293-296.

Fully, G. (1956). Unenouvelle method de determination de la taille, Annales de Medicine Legale et Criminologie, 36, 266-273.

Holliday, T. W. (2002). Body size and postcranial robusticity of European Upper Paleolithic hominins. Journal of Human Evolution, 43(4), 513-528. DOI: 10.1006/ihev.2002.0590 
İnal, H. S. (2017). Spor ve Egzersizde Vü̈ut Biyomekaniği, Hipokrat Kitabevi: Ankara.

Lundy, J. K. (1985). The mathematical versus anatomical methods of stature estimate from long bones, American Journal of Forensic Medicine and Pathology, 6(1), 73-76. DOI: 10.1097/00000433198503000-00013

Mahakkanukrauh, P., Khanpetch, P., Prasitwattanseree, S., Vichairat, K, ve Case, D. T. (2011). Stature estimation from long bone lengths in a Thai population, Forensic Science International, 210(13), 279.e1-279.e7. DOI: 10.1016/i.forsciint.2011.04.025

Özaslan, A., İşcan, M. Y., Özaslan, İ., Tuğcu, H., ve Koç, S. (2003). Estimation of stature from body parts, Forensic Science International, 132(1), 40-45. DOI: 10.1016/S03790738(02)00425-5

Pelin, C. (2014). Farkh Sosyoekonomik Katmanlarda Tibia Uzunluğundan Boy Tahmini, Yayımlanmamış Doktora Tezi, Marmara Üniversitesi Tip Fakültesi, Adli Tıp Anabilim Dalı, İstanbul.

Pelin, C., Zağyapan, R., Yazici, C., ve Kürkçüoğlu, A. (2010). Body height estimation from head and face dimensions: a different method, Journal of Forensic Sciences, 55(5), 1326-1330. DOI: 10.1111/j.1556-4029.2010.01429.x

Rago, V., Brito, J., Figueiredo, P., Carvalho, T., Fernandes, T., Fonseca, P. Ve Rebelo, A. (2018). Countermovement Jump Analysis Using Different Portable Devices: Implications for Field Testing, Sports, 6(91), 1-15.DOI: 10.3390/sports6030091

Whittle, M. (2007). Gait Analysis: An Introduction, ButterworthHeinemann Elsevier: Philadelphia.

Wilson, R. J., Herrmann, N. P., ve Jantz, L. M. (2011). Evaluation of stature estimation from the data base for forensic anthropology, Journal of Forensic Sciences, 55(3), 684-689. DOI: 10.1111/j.1556-4029.2010.01343.x 